
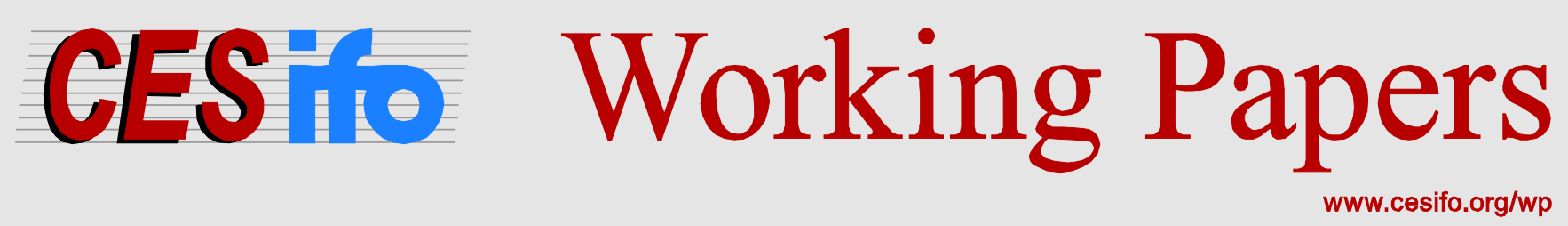

\title{
Rig Rates and Drilling Speed: Reinforcing Effects
}

\author{
Petter Osmundsen \\ Kristin Helen Roll
}

\author{
CESIFO WORKING PAPER NO. 5895 \\ CATEGORY 12: EMPIRICAL AND THEORETICAL METHODS \\ MAY 2016
}

An electronic version of the paper may be downloaded

- from the SSRN website:

- from the RePEc website:

- from the CESifo website:

www.SSRN.com

www.RePEc.org

www.CESifo-group.org/wp 


\title{
Rig Rates and Drilling Speed: Reinforcing Effects
}

\begin{abstract}
This paper studies how drilling costs are affected by the business cycle. We decompose the major elements in these costs - rig rates and drilling speed -- and examine how they interact with variations in oil prices. A highly relevant consideration in the current circumstances is whether oil companies can compensate for falling oil prices not only by driving down rig rates but also by stepping up drilling speeds. By constructing an econometric model for producing estimates, we find that both high rig rates and reduced drilling productivity will contribute to raising the cost of drilling in boom times, while the reverse is true when oil prices fall. This is good news for an oil industry under challenge. At the same time, the reinforcing effects of two major drilling cost components can explain some of the substantial cyclicality which characterises the oil industry.
\end{abstract}

JEL-Codes: C510, D240, E320.

Keywords: drilling speed, rig rates, business cycle.

Petter Osmundsen

University of Stavanger / Norway

petter.osmundsen@uis.no
Kristin Helen Roll

University of Stavanger \& University

College of Southeast Norway / Norway

kristin.h.roll@uis.no 


\section{Introduction}

We have recently seen falling oil prices combined with sticky costs at a peak stage in the business cycle for the petroleum industry. The consequent project postponements and exploration budget cuts are challenging for replacement of reserves by the oil companies and, potentially, security of supply for consumers. One part of the exploration sector where costs have been particularly high is drilling.

Since prices have been volatile, the past few decades provide a good window for investigating the impact of business cycles in the oil industry on exploration. Petroleum operations on the Norwegian continental shelf (NCS), for example, have been characterised for 10 years - as in other petroleum provinces - by a shortage of rigs and very high rates for such units, making drilling very expensive. ${ }^{1}$ At the same time, a decline in drilling speed has reinforced the cost rise. ${ }^{2}$ Clear indications that the position is reversed have recently been seen, with a large oversupply of rigs reported. Rig rates are now reportedly less than USD 200,000 per day, which is below operating cost and a huge drop from the peak of USD 600,000 per day. ${ }^{3}$ Substantial increases in drilling productivity are being reported at the same time. KCA Deutag, for example, reports a 25 per cent increase in drilling productivity on the NCS over the past year. ${ }^{4}$

We want to examine whether the seemingly inverse relationship between rig rates and drilling speed is a prevalent feature of this business. Figure 1 does indicate a negative relationship between rig rates and drilling productivity.

\footnotetext{
${ }^{1}$ Skjerpen et al (2015).

${ }^{2}$ Osmundsen et al $(2010,2012)$.

${ }^{3}$ Dagens Naringsliv, 17 March 2016.

${ }^{4}$ Dagens Naringsliv, 8 April 2016.
} 


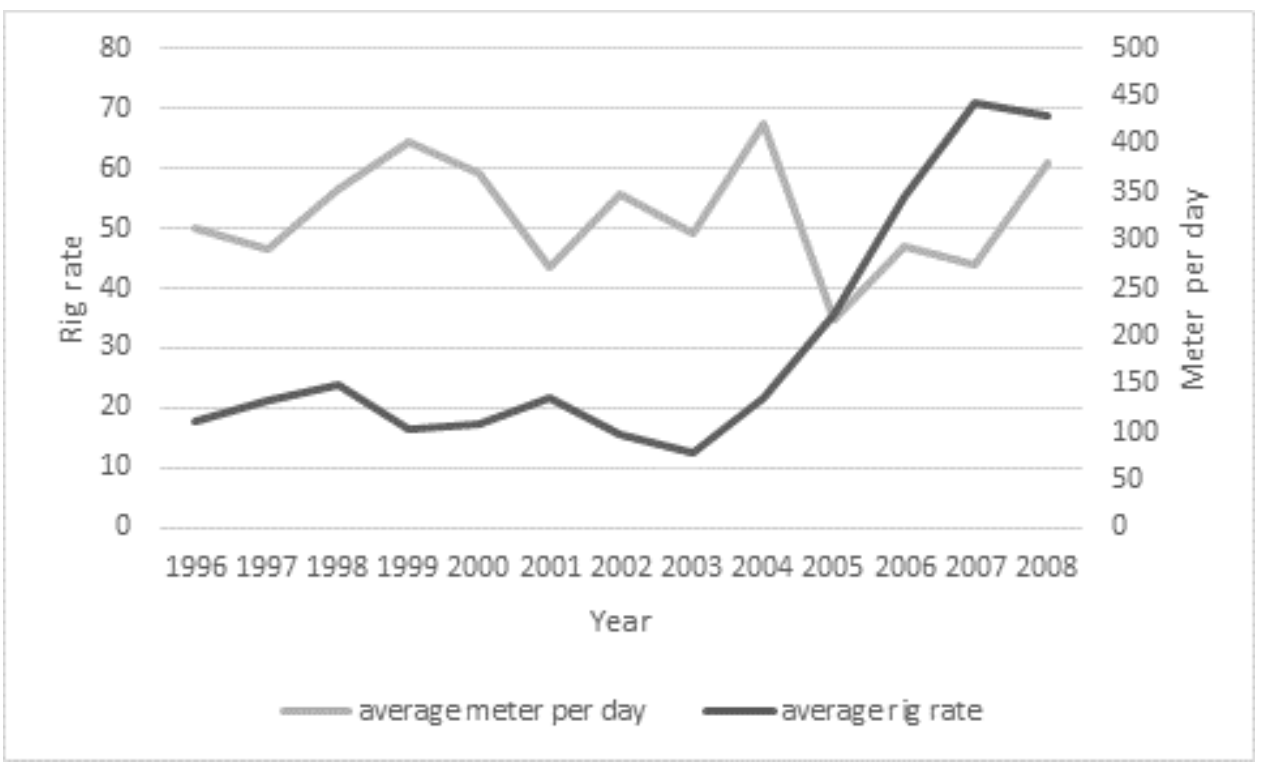

Figure 1. Average metres per day for exploration wells and average rig rates for jackups on the NCS, 1996-2008. Source: NPD and RS Platou Clarksons.

In this paper, we examine the relationship between drilling speed, measures by the industry, standard metres per day $(\mathrm{m} / \mathrm{d})$, and rig rates while controlling for other factors which affect drilling speed (such as physical characteristics of the well and its location).

Crucial determinants for drilling costs are the rig rate and drilling time, where the rig rate and drilling productivity (and thereby the time taken) vary over the business cycle. Our question is what happens to drilling speed as rig rates increase (or decrease). Might the oil companies seek to compensate for the high rig rate by increasing drilling speed? Alternatively, might one expect that, as in other sectors, productivity increases as the business cycle moves into negative territory, marginal projects are put on hold and companies are forced to retool and reorganise cumbersome processes? If that is the case, recessions can contribute to significant productivity improvements.

The rest of the paper is organised as follows. We review the existing literature in the next section, before presenting the econometric model to be constructed and then describing our data set in section 3. Empirical results from the model are presented and discussed in section 4 before section 5 concludes.

\section{Existing literature}


This paper studies how drilling operations are affected by the business cycle. Starting with the seminal work of Schumpeter (1934), a large literature exists on the economic effects of a business cycle. Among the most important basic facts is that, during a business cycle upturn, wages increase and labour productivity decreases. The opposite is true in a downturn, as pressure on wages is reduced and labour productivity rises because less productive workers depart and remaining employees work harder.

In investigating factors which influence drilling productivity, our research builds on previous articles by Aadnøy (1999), Managi et al (2005), Kaiser and Pulsipher (2007) and Osmundsen et al (2010; 2012). Moreover, Kaiser (2009) shows how drilling factors can be quantified in a predictive model.

Our research complements Aadnøy (1999). Where the latter applies qualitative methods to examine the relation between physical well characteristics and $\mathrm{m} / \mathrm{d}$, however, we use an econometric approach to an extensive data set of Norwegian offshore exploration wells. This paper is therefore more in line with Osmundsen et al $(2010 ; 2012)$. However, our focus is different, since we study the relationship between rig rates and drilling speed (measured as $\mathrm{m} / \mathrm{d}$ ). To our knowledge, little research has been done on understanding this relationship. However, related studies do exist. Osmundsen et al (2015) examine the formation of rig rates for jack-ups in the Gulf of Mexico, and Skjerpen et al (2015) look at rig rate formation and the utilisation rate for floaters on the NCS. While the focus in these papers is on understanding rig rate formation, we examine how the rig rate influences drilling speed.

\section{Empirical specification and data}

To ascertain the true effect of rig rates on drilling speed, we need to control for various technical parameters which affect the latter. A unique data set provided by the Norwegian Petroleum Directorate (NPD) allows us to apply econometric analyses to identify vital factors for explaining variations in drilling productivity over time and between different wells on the NCS. This data set contains information on well characteristics and time spent drilling. ${ }^{5} \mathrm{We}$

\footnotetext{
${ }^{5}$ Parts of the data set for exploration drilling on the NCS employed in this paper has been analysed previously to ascertain determinants for variations in the overall exploration level and reserve generation. With well count as the dependent variable, Mohn and Osmundsen (2008) specify and construct an econometric model of exploration and appraisal drilling for the NCS. Explanatory variables include oil prices, accumulated discoveries and acreage open for exploration. In a simultaneous error-correction model for drilling efforts, drilling success, and average discovery size, Mohn (2008) applies the same underlying data set to study reserve additions from NCS oil and gas exploration. The data are used by Osmundsen et al (2010) to investigate the relationship between drilling speed and the physical characteristics of well and location, and by Osmundsen et al (2012) to investigate the impact of learning effects on drilling productivity.
} 
have monthly time series for all exploration wells and supplementary variables for the period 1965-2008, split between the three major regions of the NCS. ${ }^{6}$

Summary statistics for the data sample are provided in Table 1.

\begin{tabular}{l|rrrr} 
Variable & Mean & Std. Dev. & Min & Max \\
\hline Metres per day drilled & 50.026 & 20.123 & 7.794872 & 92.22222 \\
Rig rate & 188.928 & 120.812 & 65.00 & 475 \\
Drilling fluid density & 1.561 & 0.277 & 1.03 & 2.16 \\
Well depth & $2,970.760$ & $1,150.559$ & 109.00 & $5,717.00$ \\
Water depth & 363.706 & 326.943 & 58.00 & $1,721.00$ \\
Trend & 35.295 & 3.824 & 1.00 & 13.00 \\
Tech_semi-submersible & 0.842 & 0.366 & 0 & 1.00 \\
Tech_jackup & 0.103 & 0.305 & 0 & 1.00 \\
Tech_drillship & 0.055 & 0.228 & 0 & 1.00 \\
Well purpose & 0.760 & 0.428 & 0 & 1.00 \\
Area_Norwegian Sea & 0.075 & 0.265 & 0 & 1.00 \\
Area_Barents Sea & 0.459 & 0.500 & 0 & 1.00 \\
Area_North Sea & 0.466 & 0.501 & 0 & 1.00 \\
Discovery well & 0.397 & 0.491 & 0 & 1.00
\end{tabular}

$\mathrm{M} / \mathrm{d}$ drilled are measured as total metres drilled from the seabed to the bottom of the well, divided by the number of days from initiating activity to terminating it - including days with no or little drilling activity (downtime). The rig rate variable is constructed as the average mean of a high and a low Norwegian rig rate within a month, and is measured in USD 1,000 per day. Well depth is measured in metres, with metres drilled starting at the seabed, while water depth measures the distance from the seabed to the surface. The density variable is measured as the maximum lithostatic pressure in the drilling fluid. Unobserved technical change is controlled for by a time trend (TC) where 1996=1, which captures the productivity contribution of numerous innovations in drilling introduced during the data period.

Differences in technology are accounted for by including dummy variables (Tech) which distinguish between semi-submersibles, jackups and drillships. The semi-submersible is used as the reference category, since it is the most widely used technology. The well purpose variable controls for structural differences in $\mathrm{m} / \mathrm{d}$ between wildcat and appraisal wells, where the dummy variable is one if the well is a wildcat and zero when it is for appraisal. The discovery well variable (Disc) indicates whether the well resulted in a discovery, with the dummy variable as one if that was the outcome. The area dummies (Area) control for region-

\footnotetext{
${ }^{6}$ For details on NCS resources and participants, see Facts (2012).
} 
specific effects. The wells have been drilled in the three major regions on the NCS - the North, Norwegian and Barents Seas. The Norwegian Sea is used as the reference category.

As can be seen from table 1, large spread in drilling speed and physical characteristics is found within the sample wells. Drilling speed for the average well is $50 \mathrm{~m} / \mathrm{d}$, ranging from a minimum of $7.8 \mathrm{~m} / \mathrm{d}$, to a maximum of $92.2 \mathrm{~m} / \mathrm{d}$. A large spread also exists in the rig rate, with the highest being over seven times more than the lowest.

We had to exclude some observations in the original data set because of missing observations for key variables in our econometric model - density variables, for example. Furthermore, the construction of the depth variable meant that some observations acquired a negative depth. These were removed from the sample. Some wells had also encountered major problems during drilling which led to weeks of downtime and therefore a very low $\mathrm{m} / \mathrm{d}$ measure. Since these few data points would have had a substantial effect on the results, they were considered to be outliers and removed from the sample. Furthermore, some of the observations in the original data set related to sidetracks from the original exploration well. Including sidetracks in the estimating sample causes bias since they benefit in terms of drilling time from partial utilisation of the original well. After exclusions owing to missing observations, outliers and sidetracks, we were left with 145 observations as the basis for making estimates.

The model is specified as a Cobb-Douglas function, which means that the estimated parameters can be interpreted as elasticities. The model takes the following form:

$$
\begin{aligned}
& \operatorname{In}(m / d)=\beta_{0}+\beta_{\text {rigrate }} \text { InRigRate }+\beta_{\text {depth }} \operatorname{In} \text { Depth }+\beta_{\text {pressure }} \operatorname{In} \text { Pressure }+\beta_{\text {wdepth }} \operatorname{In} \text { Wdepth } \\
& +\sum_{f} \beta_{f} \text { Tech }{ }_{f}+\beta_{\text {purpose }} \text { Purpose }+\sum_{a} \beta_{a} \text { Area }_{a}+\beta_{T C} T C+\beta_{\text {disc }} \text { Disc }
\end{aligned}
$$

where the dependent variable in our model is average $m / d$ drilled and represents drilling productivity. The explanatory variables include rig rate (RigRate), drilling depth (Depth), well pressure (Pressure), water depth (Wdepth), rig technology (Tech), well purpose (Purpose), well area (Area), technical change (TC) and whether the well makes a discovery (Disc). The $\beta$ stands for a parameter to be estimated. The choice of relevant variables has been determined in cooperation with drilling experts. By including as many relevant variables as possible, we try to separate each effect to see how it affects $\mathrm{m} / \mathrm{d}$. 


\section{Empirical results}

The production function was first estimated using ordinary least squares (OLS). A Hausman test indicated that rig rates are endogenous, ${ }^{7}$ and the model has therefore been reestimated using a generalised method of moments (GMM) instrumental variable technique. Table 1 presents the parameter estimates from the second stage regression. ${ }^{8}$ All the technical variables which influence drilling speed are statistically significant at a five per cent level, and all the estimator signs accord with the expectations of drilling experts. That indicates they are important in explaining drilling speed. Moreover, the purpose of the drilling variable is not significant and drilling speed is accordingly independent of purpose. No evidence of technical change can be seen in the period, but some differences exist between regions and technologies.

Table 1: Economic results of the model.

\begin{tabular}{|l|r|r|r|}
\hline Variable & Parameter & \multicolumn{1}{|l|}{ Std error } & $\mathrm{P}>\mathrm{z}$ \\
\hline Rig rate & -0.4591 & 0.2177 & 0.0350 \\
\hline Drilling depth & 0.4954 & 0.1003 & 0.0000 \\
\hline Well pressure & -1.5729 & 0.3045 & 0.0000 \\
\hline Water depth & -0.3617 & 0.0706 & 0.0000 \\
\hline Technical change & 0.0361 & 0.0243 & 0.1380 \\
\hline Well purpose & 0.1311 & 0.0885 & 0.1390 \\
\hline$D_{\text {Tech1 }}$ & -0.4450 & 0.1322 & 0.0010 \\
\hline$D_{\text {Tech2 }}$ & 0.0394 & 0.1806 & 0.8270 \\
\hline$D_{\text {area1 }}$ & -0.0175 & 0.1403 & 0.9010 \\
\hline$D_{\text {area2 }}$ & -0.1121 & 0.1023 & 0.2730 \\
\hline$D_{\text {Discovery }}$ & -0.2148 & 0.0788 & 0.0060 \\
\hline Constant & 2.6775 & 0.8950 & 0.0030 \\
\hline
\end{tabular}

Our main interest in this paper is how rig rates influence drilling productivity. According to Table 1 , the mean elasticity of rig rates on drilling productivity is -0.46 . In other words, a one per cent increase in the rig rate leads to a 0.46 per cent decrease in drilling productivity. Two

\footnotetext{
${ }^{7}$ The $\mathrm{t}$ statistics for the residual from the reduced form have a $\mathrm{p}$ value of 0.050 , which indicates endogeneity.

${ }^{8}$ From the first stage regression, we find that the $\mathrm{F}$ value is 28.3429 , which indicates that our estimation is strong.
} 
reasons account for the rise in drilling costs during periods of economic expansion: 1) higher rig rates and 2) reduced drilling productivity. The latter may seem counterintuitive, but can be explained by a shortage of the most productive rigs and competent personnel in boom times. High rig rates are associated with a buoyant business cycle for the oil industry. A high level of activity implies scarcity of rigs and key people. Less adequate rigs and less competent personnel are therefore being used at the margin, and reduce average productivity. With a peaking business cycle for the oil industry, moreover, bottlenecks are more likely to appear for other crucial drilling supply services and thereby drive up non-productive time. Conversely, rig rates decrease while productivity increases in times of economic recession like those we are now experiencing. . Both these factors contribute to reduced drilling costs. This finding is particularly important at times like the present, when many firms are struggling because of low oil prices and limited activity. The decrease in drilling costs can be crucial for survival in such periods.

All other things being equal, drilling depth has a positive and significant effect on $\mathrm{m} / \mathrm{d}$ and indicates the presence of economies of scale in the operation. That supports the findings of Osmundsen et al (2013), who report a positive but decreasing effect from drilling depth.

Density is found to have a large negative effect on $\mathrm{m} / \mathrm{d}$, with a highly significant elasticity estimate of -1.57. This is as expected, since a higher well pressure requires an increase in mud weight and thereby reduces drilling speed. Large water depth is found to have the same effect. That is again not surprising, since our drilling measure starts at the seabed. Thus, a large water depth adds to drilling time without contributing to $\mathrm{m} / \mathrm{d}$ - the key performance indicator.

Wells which yield a discovery (Disc) are found to take 21.5 per cent longer to drill on average than dry wells. This is also not surprising, owing to the time spent on testing a discovery. Similarly, the Purpose dummy variable, which specifies whether the well is a wildcat or an well, indicates that productivity is greater at 10 per cent level for the former than the latter. On average, wildcats are 13.1 per cent faster to drill than appraisals. This can be explained by the fact that more tests are done while drilling appraisal wells.

The variables which control for different drilling technologies indicate that jackups are slower on average than either a semi-submersible or a drillship. On the other hand, we cannot find any significant difference in $\mathrm{m} / \mathrm{d}$ between a semi-submersible and a drillship. However, this result is uncertain since almost all the wells were drilled by a semi-submersible. 


\section{Conclusion}

This paper studies how drilling costs are affected by the business cycle. A multivariable econometric model is used to investigate the influence of rig rates on drilling speed, drawing on data from the NCS. This case is particularly interesting, since oil prices have been especially volatile over the past decade and have thereby generated substantial business cycles in the rig market. The current downturn is characterised by analysts and industry experts as the worst ever. ${ }^{9}$ Beside rig rates, our model also controls for a number of other physical characteristics of the well and its location which are expected to affect drilling speed.

The results indicate that the rig rate has a negative effect on drilling productivity or, in other words, that drilling speed will decrease at times when the rig rate is high. During economic booms, drilling costs will thereby rise because of both high rig rates and lower drilling productivity. The reinforcing effect of these two factors can thereby explain some of the substantial cyclicality which characterises this industry.

On the other hand, rig rates decrease while productivity increases at times of economic recession, like the one we are currently experiencing. Both of these developments contribute to reducing the cost of drilling. This finding is particularly important in times like these, when many companies are struggling as a result of low oil prices and limited activity. A decline in drilling costs could prove vital for maintaining operations in the petroleum industry. This is a crucial factor in reducing breakeven prices for new development projects. Statoil, for example, has announced that it has reduced the breakeven price for the Johan Castberg field in the Barents Sea, which it operates, from USD 80 per barrel to USD 45. The cost per well has been cut by USD $123,000 .^{10}$

\section{References}

Aadnøy, B.S. (1999). Modern Well Design. Balkema, Rotterdam.

\footnotetext{
${ }^{9}$ Dagens Naringsliv, 17 March 2016.

${ }^{10}$ Dagens Naringsliv, 19 April 2016.
} 
Facts (2012). A general overview of information regarding the petroleum activities on the Norwegian continental shelf, published by the Ministry of Petroleum and Energy with the Norwegian Petroleum Directorate.

Kaiser, M.J. and Pulsipher, A.G. (2007). “Generalized Functional Models for Drilling Cost Estimation”. SPE Drilling \& Completion 22(2), SPE 98401, June 2007, 67-73.

Managi, S., Opaluch, J.J., Jin, D. and Grigalunas, T. A. (2005), Technological change and petroleum exploration in the Gulf of Mexico. Energy Policy 33 (5), 619-632.

Mascarenhas, B. and Aaker, D. (1989). Strategy over the business cycle. Strategic Management Journal, 10(3), 199-210.

Osmundsen, P. and Roll, K.H. (2013), Concave Drilling Curve, proceedings, IAEE European Conference 2013, Dusseldorf, 18-21 August 2013.

Osmundsen, P., Roll, K.H. and Tveterås, R. (2012), Drilling speed - the relevance of experience, Energy Economics 34, 786-794.

Osmundsen, P., Roll, K. and Tveterås, R. (2010), Exploration Drilling Productivity at the Norwegian Shelf, Journal of Petroleum Science and Engineering, 73, 122-128.

Osmundsen, P., Rosendahl, K. E. and Skjerpen, T. (2015). Understanding rig rate formation in the Gulf of Mexico. Energy Economics, 49, 430-439.

Schumpeter, J. A. (1934). Theory of Economic Development. Harvard University Press, Cambridge, MA.

Skjerpen, T., Storrøsten, H. B., Rosendahl, K. E. and Osmundsen, P. (2015). Modelling and forecasting rig rates on the Norwegian Continental Shelf, Statistics Norway (Working paper No 832). 